\title{
APPROACH CATEGORY UPGRADE AT SARAJEVO INTERNATIONAL AIRPORT
}

\author{
Nermin Zijadić ${ }^{1}$, Edvin Šimić ${ }^{2}$ Muharem Šabićc ${ }^{3}$ \\ ${ }^{1}$ PC Sarajevo International Airport LLC, Sarajevo/71000, Bosnia and Herzegovina \\ 2,3 Department of Air Transport, Faculty of Transport and Communications, University of Sarajevo, \\ Sarajevo 71000, Bosnia and Herzegovina
}

Received 26 May 2020; accepted 12 June 2020

\begin{abstract}
The Instrumental Landing System (ILS) system has been used for decades as an irreplaceable navigation aid at most international airports worldwide. Older radio navigation aids are very reliable, and still in use, although are very complex with high maintenance and installation costs. Due to increased traffic and limited peak hour capacity, the need for new technological solutions arises. Global Navigation Satellite System (GNSS) based navigation is already widely used in the aviation sector. This paper will provide decision-makers, involved in the development strategy for Sarajevo International Airport, a clear insight into the benefits of Ground Based Augmentation System (GBAS) over the classic ILS system. Besides, it describes several essential steps to research before implementing GBAS Category (CAT) II / III system. Sarajevo Airport has many limiting factors regarding the installation of a higher ILS category system, so this article proposes a solution in the form of a GBAS system, and analyse how it will affect the Sarajevo airport operations, especially in low visibility conditions.
\end{abstract}

Keywords: satellite navigation, approach, weather, GBAS.

\section{Introduction}

Sarajevo airport is located $8 \mathrm{~km}$ northwest of the city centre. The airport is surrounded by high mountains, except in the northwest, where there is an open field towards the Bosna river valley. This terrain configuration prevents the warm Mediterranean air from entering the valley, which is why we have a pronounced continental climate. The airport is in the vicinity of the slopes of the mountains, and in the winter months, the cold air descends into the valley which causes fog formation (see Fig. 1). Besides, there are also many rivers with their tributaries, which contribute to increased humidity.

\footnotetext{
${ }^{1}$ Corresponding author: nermin.zijadic@sarajevo-airport.ba
} 


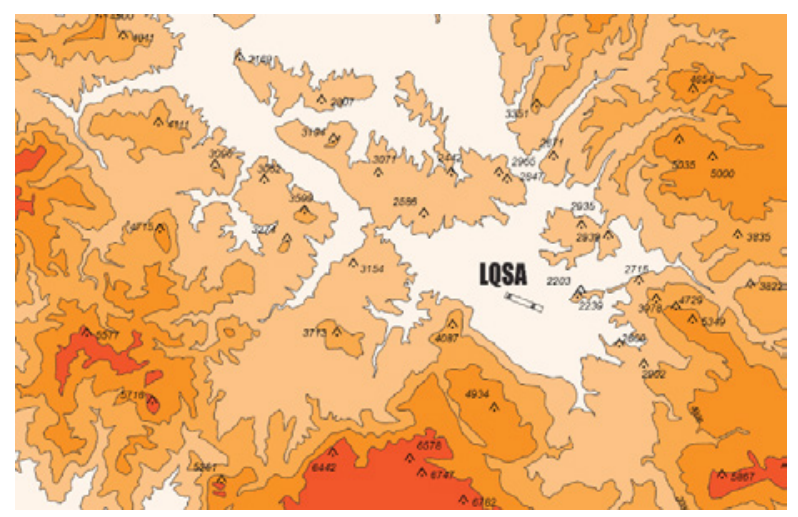

Fig. 1.

Sarajevo Airport with Surrounding Mountainous Terrain

Source: (AIP, 2019)

With the significant prevalence of anticyclone and temperature inversion, low ceiling and fog are present, which are particularly pronounced between November and the beginning of March. The most frequent type of fog is radiation fog. Fog development is strongly associated with aerosols condensations in the air, especially in environments where we have a large number of pollutants in winter months. The most common winds are NW-SE and NNW-SSE. Surrounding terrain has a great influence on wind direction and intensity. These winds do not significantly affect takeoff and landing operations, however, they do affect the intensity and duration of the fog, as they allow air stagnation and cooling (Milosevic et al., 1986). All mentioned weather conditions cause a significant decline in the number of operations during winter months, especially in the morning and evening hours, when visibility and ceiling are low. In addition to poor visibility, Sarajevo
Airport has issues with other meteorological events such as heavy snowfall and strong southerly winds.

\section{Current ILS CAT I at Sarajevo International Airport}

The first thing we need to analyze is the meteorological parameters that affect traffic operation. As shown in Fig. 2, we see Runway Visual Range data (RVR) visibility data, which is distributed hourly. Data shows that the significant low visibility occurrences are most pronounced in the morning hours when we usually have traffic rush hours. Data were taken between 2014 and 2020. We analyzed months of December and January when we had major operation cancellations due to low visibility. The line represents the number of Meteorological Aerodrome Reports (METAR) for a given period and the horizontal axis represents 24 Universal Time Coordinate (UTC) hours time frame. 


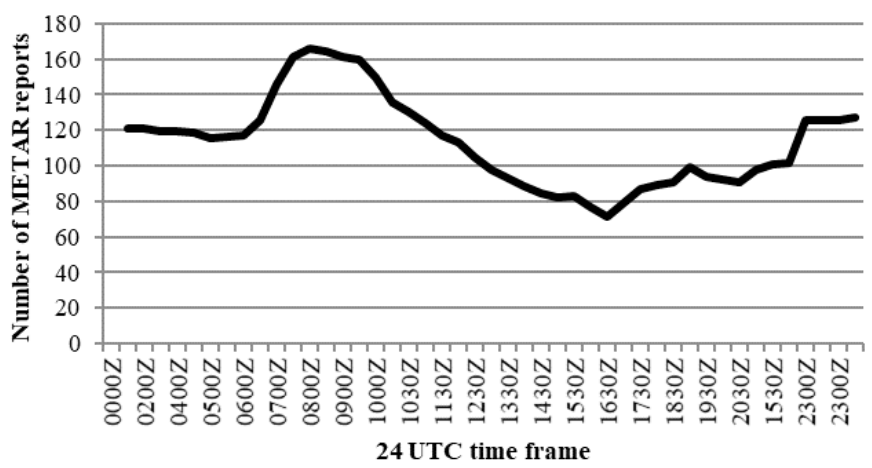

Fig. 2.

Number of METAR Reports with Notified RVR below $1000 \mathrm{~m}$ in the 24-hour Period for December and January Source: Own Edition

Sarajevo Airport is also certified for Low Visibility Procedures (LVP). The introduction of LVP procedures allows the operation to be performed on conditions that are less than the minimum conditions for CAT I category, primarily concerning RVR parameters. At Sarajevo airport, Runway (RWY) 29 is suitable for non guided Low Visibility Take Off (LVTO), however, for RWY 11 only visual departure is possible. The fixed minimum required RVR value for LVTO at Sarajevo airport is $200 \mathrm{~m}$ for non-guided LVTO and only conducted when RVR is below $400 \mathrm{~m}$ (BHANSA, 2015).

Currently, Sarajevo Airport is equipped with Thales' CAT I ILS/DME, (type ILS 381), with identification „BHS“, Localizer frequency $110.7 \mathrm{MHz} /$ Glide Path (GP) Frequency: $330.2 \mathrm{MHz}$ with Distance measuring equipment (DME) on Channel $44 x$, ILS, co-located with the glide path antenna. The middle marker is located at $900 \mathrm{~m}$ from the runway threshold 11 and the GP approach angle is 3.2 degrees. All Standard Instrument Departures (SID) from Sarajevo require aircraft to maintain higher than normal climb rates until above the surrounding terrain. This requirement is introduced to manage the descent of arriving aircraft to accommodate a suitable profile to safely establish on the ILS runway 11 (BHANSA, 2015). Due to surrounding mountainous terrain, a higher approach angle is needed for landing and missed approach procedures. One limiting factor for higher ILS category implementation is the pre - threshold terrain of runway 11 . There is a defined distance before the runway threshold, which must be obstacle-free for normal radio altimeter operation. 


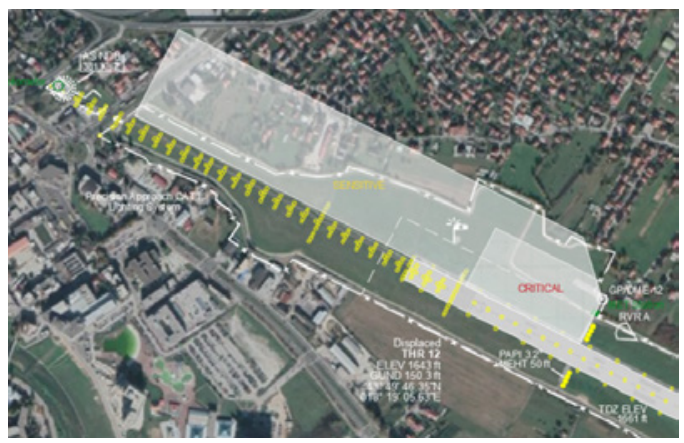

Fig. 3.

CAT I Critical and Sensitive Area for Sarajevo Airport Runway 11

Source: Own Edition

The ILS system is installed in the runway close vicinity and is subjected to multipath effects which place restrictions on further airport infrastructure development and also limit the aircraft movements. Spacing under low visibility conditions must be significantly increased due to potential reflections or distortions of the guidance signals by preceding aircraft (Felux, Dautermann and Becker, 2013). Due to the ILS signal protection, sensitive areas become larger and aircraft entering the runway areas are required to hold on the CAT III holding points as opposed to CAT I holding points, which are closer to the runway. This results in restricted ground movements and greater final approach spacing margins between aircraft to accommodate the subsequently longer Runway Occupancy Times (ROT). As shown in Fig. 3, higher than ILS I category will require creating larger sensitive areas in already limited space, due to residential buildings in the pre threshold terrain. Another important factor is a current approach lighting system that has to be upgraded as a requirement for higher precision categories. The current system is Approach Light System, with Sequenced Flashing Lights -ILS Cat-I (ALSF -I) configuration, as shown in Fig. 3. Essentially, for higher ILS categories the lights should be installed inside the urban area in the pre-threshold area of the runway 11 , which is another limiting factor.

Higher ILS category enables lower minimums, however, the problem would appear in the Missed Approach segment. The Missed Approach Climb Gradient (MACG) would have to be larger, which is restrictive since we have high terrain immediately after the runway in the missed approach procedure. Another issue of Sarajevo Airport is traffic nature, take-offs and landings are conducted in the opposite direction (departing from runway 29 and landing on runway 11), which significantly reduces the runway capacity.

To look at the benefits of implementing a GBAS system, it is necessary to look at the factors that affect visibility. Based on the number of flights cancelled due to reduced visibility, we can conclude that the highest number is in December. Figure 4 shows all cancelled flights that match meteorological conditions where visibility was below $1000 \mathrm{~m}$ and the ceiling was overcast or broken below $1000 \mathrm{ft}$. On the right figure, we notice a significant number of cancelled flights during the morning, afternoon, and evening hours. 

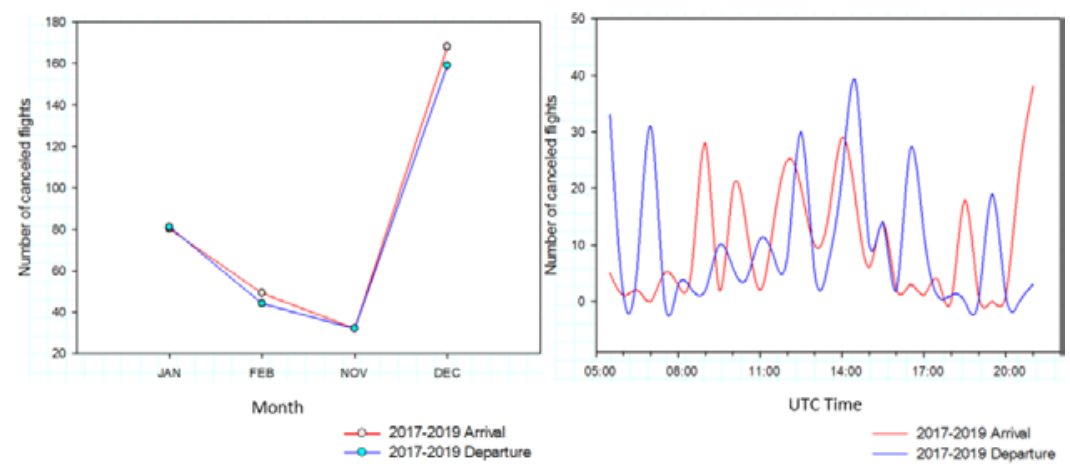

Fig. 4.

Month and Hour Distribution of Canceled Arrival and Departure Flights from 2017 to 2019 at Sarajevo International Airport

Source: Own Edition

\subsection{Possible Installation of Higher ILS Categories}

To introduce higher ILS categories, it is necessary to have certain conditions on the runway and in the pre-threshold terrain profile. While terrain under the approach path should be relatively level, concerning the runway surface, there will usually be irregular contours ahead of the threshold (Transport Canada, 2011). Radio altimeters operate on the principle of measuring the time interval required for electromagnetic waves emitted from aircraft to reach the ground, bounces back, and return to the aircraft (Šabić, 2016). Due to the importance of radio altimeters function in determining the decision height, several conditions must be met. As stated in (Transport Canada, 2011), the terrain should be free of significant obstacles to ensure the proper function of the radio altimeter during a critical phase of descent, from a distance of at least $3,000 \mathrm{ft}$ ahead of the threshold, and a width of $100 \mathrm{ft}$ on either side of the extended runway centerline.

According to (Transport Canada, 2011), gentle terrain changes may be acceptable up to $+-5 \mathrm{ft}$, or isolated sudden changes up to $10 \mathrm{ft}$. However, any repetitive abrupt changes should be restricted to less than $3 \mathrm{ft}$ in distance and preferably should be avoided. Single buildings of heights up to $10 \mathrm{ft}$ can be tolerated if their length is less than $50 \mathrm{ft}$ measured parallel to the centerline. We can conclude that the Sarajevo airport pre-threshold area has a significant number of obstacles in the form of solid buildings, which certainly disrupt a normal radio altimeter operation. If the airport does not meet those conditions additional analysis should be conducted by the responsible aviation authorities. Another requirement is related to the height at the point where Decision Height $\mathrm{DH}$ is reached. $\mathrm{DH}$, in this case, will be the minimum above the highest obstacle in the first $3000 \mathrm{ft}$ of the runway, but the radio altimeter will, at this point on the glide path, be measuring the height distance immediately below the aircraft (Transport Canada, 2011).To determine the required radio altimeter reading when $\mathrm{DH}$ is reached, profile charts are required, which provide elevation information for the first 3,000 ft of the runway. Knowing the glide path angle and the glide path 
intercept point, the required reading on the radio altimeter at $\mathrm{DH} /$ alert height can be calculated (Transport Canada, 2011). Following ICAO Annex 4, Chapter 6 every airport should have a pre-threshold terrain profile charts.
Using the data from Sarajevo Airport, Table 1 represents the monthly operations for existing CAT I and corresponding possible CAT II/III. It is obvious, that for arrival operation, with CAT II/III condition all operation would be possible.

\section{Table 1}

Cancelled Arrival Flights for Airport Sarajevo in the Period 2017-2019

\begin{tabular}{|c|c|c|c|c|c|c|c|c|c|c|c|c|c|c|}
\hline & Cloud base & Visibility/ RVR & \multicolumn{4}{|c|}{2017} & \multicolumn{4}{|c|}{2018} & \multicolumn{3}{c|}{2019} \\
\hline & & & JAN & FEB & NOV & DEC & JAN & FEB & NOV & DEC & JAN & FEB & NOV & DEC \\
\hline CAT I & $200 \mathrm{ft}$ & $<550 \mathrm{~m}$ & 2 & 0 & 0 & 26 & 4 & 0 & 0 & 9 & 6 & 1 & 0 & 19 \\
\hline CAT II/III & $50 \mathrm{ft}$ & $<50 \mathrm{~m}$ & 0 & 0 & 0 & 0 & 0 & 0 & 0 & 0 & 0 & $1^{*}$ & 0 & $1^{*}$ \\
\hline
\end{tabular}

Source: Own Edition

Note: Cloud base was $100 \mathrm{ft}$

A very similar case we have also with departure operations as shown in Table 2.

\section{Table 2}

Cancelled Departure Flights for Airport Sarajevo in the Period 2017-2019

\begin{tabular}{|c|c|c|c|c|c|c|c|c|c|c|c|c|c|}
\hline & Visibility/ RVR & \multicolumn{4}{|c|}{2017} & \multicolumn{4}{|c|}{2018} & \multicolumn{4}{c|}{2019} \\
\hline & & JAN & FEB & NOV & DEC & JAN & FEB & NOV & DEC & JAN & FEB & NOV & DEC \\
\hline CAT I & $<200 \mathrm{~m}$ & 1 & 0 & 0 & 12 & 1 & 0 & 0 & 4 & 0 & 0 & 0 & 9 \\
\hline CAT II/III & $<125 \mathrm{~m}$ & 1 & 0 & 0 & 4 & 0 & 0 & 0 & 0 & 0 & 0 & 0 & 0 \\
\hline
\end{tabular}

Source: Own Edition

\section{Characteristics of the Ground-based Augmentation System (GBAS)}

GBAS uses the concept of differential corrections to augment satellite signal enabling precision approach up to Category III (Sabatini, Moore and Ramasamy, 2017). The GBAS Approach Service Type (GAST) describes the level of usability provided by an individual station, in a similar way of ILS categories. GAST-C is intended to support precision approach operations in CAT-I minima. GAST-D concept was developed by ICAO Navigation System Panel (NSP) to allow GBAS to support CAT II/III approach and landing operations using GPS L1 frequency (Smaja, 2015).
Although, ICAO has only issued Standards and Recommended Practices (SARPs) for GBAS operating over single frequency and single constellation up to CAT I operations (Sabatini, Moore and Ramasamy, 2017). EUROCONTROL has developed several documents to support GBAS CAT I and initial GBAS CAT II/III Air Traffic Management (ATM) requirements based on ICAO standardization work (Smaja, 2015).

GBAS ground station consists of multiple reference receivers with their antennas installed on previously surveyed locations in the vicinity of the airport. The information in the receiver is sent to a processor that computes the corrections for each 
navigation satellite in view and broadcasts these differential corrections, via a VHF Data Broadcast (VDB) (Sabatini, Moore and Ramasamy, 2017). The broadcast information is received by the aircraft together with received information from the navigation satellites. Using differential correction with received satellite information the position is accurately calculated. Current certified GBAS airborne receivers and ground-based installations are limited to CAT-I operations, i.e. precision approach procedures down to decision height (height above ground at which the cockpit crew must see either the runway or at least the runway approach lights) of $200 \mathrm{ft}$ (Feuerle, Stansiak and Lipp, 2016).

\section{Open Issues with GBAS Usage}

According to (ICAO, 2018), several issues must be taken into consideration to use satellite navigation for aircraft guidance. Faults and space weather have a great impact on the integrity and accuracy of the position solution, whereas constellation and frequency interference affects the availability of the service. Due to the nature of air traffic where operations take place in very short time intervals, in critical phases, the crew under the high workload does not have time to solve navigation problems or switch to alternative ones. If the crew notice any deviations in navigation systems indicators, they will immediately cancel the approach procedure. A particular limitation is the low power of the GNSS signal and consequently is prone to jamming and spoofing.

\subsection{System Errors}

Errors could occur due to system imperfections both on satellite vehicles and in the aircraft itself. Described in the paper (Blanch, Walter and Enge, 2012), faults within a Global Navigation Satellite System (GNSS) could be attributed to clock runoff, where the signal broadcast by a given satellite is not properly synchronized to the signals from other satellites in the constellation. Each GNSS has its timing system, and hence, some intersystem clock biases should be considered when dealing with a multi-constellation system (Karaim et al., 2018). Other faults proposed in (Blanch, Walter and Enge, 2012) have been due to upload of faulty navigation data from the GPS control segment to the GPS satellites, or from unannounced manoeuvres that render the broadcast satellite position invalid.

\subsection{Space Weather}

Space weather can generate severe ionospheric disturbances. A significant concern for GBAS is the possibility that very large ionospheric gradients could cause a large spatial error decorrelation and thus induce differential position errors for arriving aircraft (Circiu et al., 2014). The sensitive monitoring for ionospheric gradients within the ground station is challenging due to strong limitations on the spacing between reference antennas (Felux, 2018). For this reason, many airports will have placing problems due to limited free suitable areas.

Another dangerous phenomenon that can affect the system is solar flares, explosions, which appear on the Sun's surface. The frequency of solar flares occurrences coincides with the 11-year solar cycle (Natras, Horozovic and Mulic, 2019). Intense data monitoring during and near the solar cycle peaks is essential for system analysis to get an insight into the real effect on GNSS precision. 
Shown in Fig. 5, an ionospheric activity can vary significantly depending on geographic longitude and latitude. As reported in a study (Balvedi, Peterson and Fregnani, 2016), Brazil is located under the geomagnetic equator, which implies that Brazilian territory is under harsh ionospheric disturbances. The amount of error introduced by these anomalies can be much greater than the correction broadcasted in the GNSS navigation message, which increases the urgency for assessing the impact of these errors in any satellite-based aeronautical navigation system.

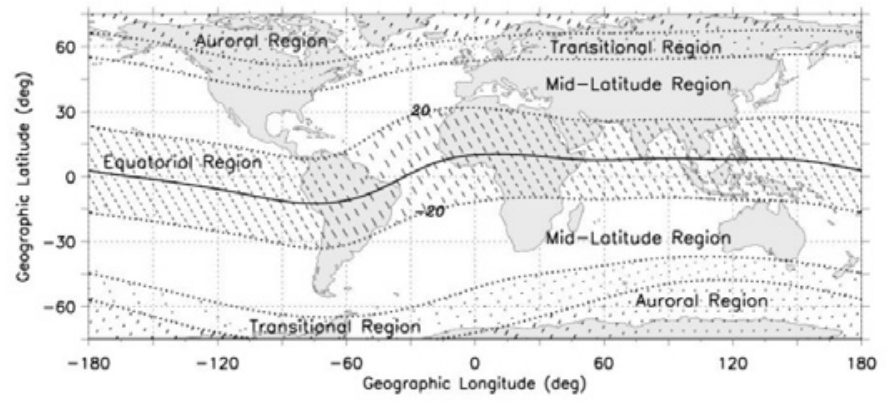

Fig. 5.

Ionospheric Regions

Source: (ICAO, 2013)

Sarajevo airport is located in the mid-latitude zone so the ionospheric disturbances are not particularly pronounced. The aim of the study (Horozovic, Natras and Tabakovic, 2018) was to broaden the research to the region of the Western Balkan to analyze the impact of solar activity on the ionosphere and on GNSS positioning estimates during two opposing periods of SC (solar cycle) 24 . The study periods were selected to be the second half of October 2014, during pronounced solar activity in the solar maximum, and the first half of September 2017 (Horozovic, Natras and Tabakovic, 2018). Before installing the GBAS system, solar activity in this area should be studied in detail, and solar patterns should be described in a larger timeframe and possibly made a local forecast model.

Applying a local ionosphere Total Electron Content (TEC) model of high spatial and time resolution for the observed area on one-frequency GNSS observations would help to check the accuracy that could be achieved compared to the usage of global models, which have limited accuracy and precision (Horozovic, Natras and Tabakovic, 2018). Local TEC model for Bosnia and Herzegovina is still under development. Using dual-frequency receivers, ionospheric errors could be minimized, however, many GNSS devices still operate on single frequency $L 1$. With introducing a second civilian frequency, the ionosphere error can also be directly corrected onboard the aircraft itself (Dautermann, 2014).

\subsection{Constellation Weakness Effects}

Dilution of precision (DOP) or geometric dilution of precision is the term that describes the positional errors related to the geometric positions of Space Vehicles (SVs) in the 
sky relative to the receiver. The better the geometry is, the lower the DOP, and, hence, the better the position solution (Karaim et al., 2018). For high precision navigation, multiple constellations of satellites are required especially due to the aircraft high speed where there is a rapid change in the tracking of the SV. Constellation strength means that the GNSS constellation is adequately replenished and that all key aircraft operations are adequately supported all of the time (Blanch, Walter and Enge, 2012). Generally, GPS users only need four satellites to estimate their position. However, aircraft on approach typically need seven or more satellites to guarantee the performance needed to ensure safe operation.

\subsection{Radio-Frequency Interference (RFI)}

RFI can be naturally or artificially induced. Artificial can be intentional and unintentional. Signals are received below the user background thermal noise level, therefore, these signals are weak and readily overwhelmed by any of the multitude of signals emanating from terrestrial sources (Blanch, Walter and Enge, 2012). Intentional interference is, in many cases, a significant source of GNSS signal degradation. Intentional interference, known as signal jamming, is caused by the broadcast of malicious radio frequency ( $\mathrm{RF}$ ) signals to prevent GNSS receivers from tracking GNSS signals in a specific area (Karaim et al., 2018). The creation of fallback systems is crucial, as well as the ability of the system to quickly return in operation if an inevitable interruption occurs.

Spoofing represents the intentional signal transmission that is providing the receiver with misleading signals. The receiver uses counterfeit signals in space and computes erroneous position calculation (Kim, Sin and Lee, 2012). Signal spoofing is more harmful than jamming because it is not readily detected (Karaim et al., 2018). Of all the errors listed above, prediction of intentional human-made errors is most demanding. Protection against such interference is under consideration for the next generation of avionics standards according to (FernándezHernández et al., 2019). Cybersecurity will have a special place in the aviation research community during the implementation of future GNSS technology.

\section{Results and Discussion}

Current civil aviation GNSS use is predominantly based on a satellite single frequency constellation, namely L 1 frequency (ICAO, 2018). ICAO standards for $L 1$ frequency have already been developed for GPS and GLONASS systems and augmentations already exist. SARPs (Standards and Recommended Practices) for dual-frequency GPS and GLONASS systems are still in development. Introducing the L5 frequency in combination with existing frequencies will significantly increase the integrity parameters of the precision guidance system.

To increase system reliability, it is necessary to improve the receiver's ability to receive signals from multiple GNSS constellations. Dual-frequency receivers could eliminate the ionospheric delay in the monitor metrics using the linear combination of the pseudorange and carrier phase measurements. GNSS constellations offering dual-frequency signals will be introduced into service during the 2020s by the United States (GPS), the Russian Federation (GLONASS), Europe (Galileo), and China (BeiDou) (ICAO, 2018). 
Standards for the CAT-II/III capable service type (GAST D) were agreed and developed by the International Civil Aviation Organization (ICAO) at the end of 2016 and will be in effect from 2018 on (Felux, 2018). Contributors for the Single European Sky ATM Research (SESAR) projects were the main manufacturers of GBAS airborne and ground equipment (namely Thales, IndraNavia, Honeywell, etc.). Table 3 shows the cost calculation or revenue loss as an example based on referenced aircraft of $77000 \mathrm{~kg}$, with 113 passengers, on-route of $1000 \mathrm{~km}$, for the three most important subject (Cost calculation is made on the basis for the scenario that flight operate in Bosnia and Herzegovina, and Airport Sarajevo):

- Air carrier lost revenue for 113 passengers with an average ticket price of $200 €$;

- Air Navigation Service Provider, lost revenue for navigation fees on EUROCONTROL basis;

- The airport at destination, lost revenue for basic aeronautical charges (landing, handling, passenger tax).

Table 3

Lost of Revenue for Single Cancelled Flight at Airport Sarajevo

\begin{tabular}{|c|c|c|}
\hline Subject & Cost structure & Cost value $[\boldsymbol{\epsilon}]$ \\
\hline Air carrier & Ticket price & 22600 \\
\hline Air Navigation Service Provider & Navigation fees & 550 \\
\hline Airport & $\begin{array}{c}\text { landing } 300+\text { handling } 500+ \\
\text { passenger tax } 10^{*} 113\end{array}$ & 1930 \\
\hline TOTAL & \multicolumn{2}{|c|}{ EUR 25 080 } \\
\hline
\end{tabular}

Source: Own Edition

For a GBAS GAST D price of $1194000 €$ (Džunda, Dzurovcin and Ondruš, 2019), not taking into account equipping aircraft, we need just 48 operations to pay off the initial investment.

Table 4 compares the ILS system with the GBAS system by several criteria. According to multiple comparisons, we conclude that
GBAS has 15 advantages of total of 24 criteria points. Multiple research has been done on this topic, however, below are presented all criteria that future users of this system will be able to evaluate and make a cost-benefit analysis. We cannot say that GBAS is a better or worse solution, though each operator will decide by its local conditions which system will meet their needs. 
Table 4

ILS and GBAS Multicriteria Comparison

\begin{tabular}{|c|c|c|c|}
\hline & Parameters & ILS & GBAS \\
\hline 1 & Signal characteristic (FAA, 2014) & Analog & Digital \\
\hline 2 & $\begin{array}{c}\text { Transmision band (Sabatini, Moore } \\
\text { and Ramasamy, 2017) }\end{array}$ & VHF and UHF (DME) & Single VHF \\
\hline 3 & $\begin{array}{l}\text { ILS lateral and vertical deviations } \\
\text { (Jeong et al., 2016) }\end{array}$ & $\pm 20 \mathrm{~m}$ on a point $18 \mathrm{NM}$ & $\begin{array}{l}\text { From the threshold to } 18 \mathrm{NM} \pm 0.5 \\
\text { and } \pm 2 \mathrm{~m}\end{array}$ \\
\hline 4 & $\begin{array}{l}\text { Expected costs of construction } \\
\text { (Džunda, Dzurovcin and Ondruš, } \\
\text { 2019) }\end{array}$ & $\begin{array}{c}\text { DME an ILS CAT II \& III } 800 \\
000 €\end{array}$ & $\begin{array}{l}\text { GBAS CAT II \& III- } \\
1194000 €\end{array}$ \\
\hline 5 & $\begin{array}{c}\text { Annual maintenance/ operations } \\
\text { cost (FAA, 2014) }\end{array}$ & Over $83500 €$ per runway & $70000 €$ for all runways \\
\hline 6 & Critical zones & $\begin{array}{c}\text { Tied to ILS critical zones to ensure } \\
\text { safety }\end{array}$ & Eliminates hold-short zones \\
\hline 7 & Touchdown zones & $\begin{array}{l}\text { Fixed glideslopes and touchdown } \\
\text { zones }\end{array}$ & $\begin{array}{c}\text { Variable glideslopes and touchdown } \\
\text { zones }\end{array}$ \\
\hline 8 & $\begin{array}{c}\text { Global acceptance (Sabatini, Moore } \\
\text { and Ramasamy, 2017) }\end{array}$ & Wide international acceptance & Still in development \\
\hline 9 & Approach support (Smaja, 2015) & $\begin{array}{l}\text { Supports a single approach for each } \\
\text { runway }\end{array}$ & $\begin{array}{c}\text { Supports multiple approaches for } \\
\text { all runways and also possible for } \\
\text { adjacent airports use }\end{array}$ \\
\hline 10 & $\begin{array}{l}\text { Position accuracy with distance } \\
\text { (Jeong et al., 2016) }\end{array}$ & $\begin{array}{c}\text { Position accuracy decreases with } \\
\text { distance from the runway threshold }\end{array}$ & Constant position accuracy \\
\hline 11 & Sensitivity to ionospheric changes & Slight & $\begin{array}{l}\text { Considerable for single-frequency } \\
\text { GNSS signal transmission }\end{array}$ \\
\hline 12 & Curved approach (ICAO, 2013) & Unable to provide & $\begin{array}{c}\text { Possible, however, there is no legal } \\
\text { basis and further research in curved } \\
\text { approaches }\end{array}$ \\
\hline 13 & Airlines usage (Näs et al., 2017) & $\begin{array}{c}\text { Rather ILS or PBN ( Performance- } \\
\text { based navigation) }\end{array}$ & $\begin{array}{l}\text { Low interest in new technology } \\
\text { investing }\end{array}$ \\
\hline 14 & Certification & Fully certified & Still in the certification process \\
\hline 15 & Wake turbulence & Constant glide path & $\begin{array}{l}\text { Flexible glide path according to } \\
\text { traffic }\end{array}$ \\
\hline 16 & Signal consistency & Not affected & $\begin{array}{l}\text { Depend on geographic latitude } \\
\text { (ionospheric disturbances) }\end{array}$ \\
\hline 17 & Traffic separation & Fixed & Reduced aircraft separation \\
\hline 18 & Sitting location & Exactly specified & More flexible \\
\hline 19 & $\begin{array}{l}\text { Manmade interference } \\
\quad(\text { ICAO, 2013) }\end{array}$ & Stable, strong signal & $\begin{array}{c}\text { The danger of jamming and } \\
\text { spoofing, due to very weak signal } \\
(-160 \mathrm{dBm})\end{array}$ \\
\hline 20 & Airspace users & Primarily airlines & $\begin{array}{c}\text { Other airspace users like unmanned } \\
\text { aerial vehicles }\end{array}$ \\
\hline 21 & Signal & Stronger & Weaker, susceptible to interference \\
\hline 22 & $\begin{array}{c}\text { Guided missed approach (Sabatini, } \\
\text { Moore and Ramasamy, 2017) }\end{array}$ & Not supported & Supported \\
\hline 23 & $\begin{array}{c}\text { System location dependence } \\
\text { (Sayim, Kavzoglu and Sahin, 2015) }\end{array}$ & $\begin{array}{c}\text { Dependant to ground infrastructure } \\
\text { only }\end{array}$ & $\begin{array}{l}\text { May be affected by masking and } \\
\text { geometries/positions in space at } \\
\text { any time. }\end{array}$ \\
\hline 24 & False capture (Smaja, 2015) & $\begin{array}{c}\text { ILS localizer false captures are } \\
\text { situations where the aircraft } \\
\text { prematurely initiates a turn onto the } \\
\text { localizer centreline }\end{array}$ & Cannot happen with GBAS \\
\hline
\end{tabular}

Source: Own Edition 


\section{Conclusion}

Considering the implementation of GBAS means an analysis of factors that affects airport capacity decline. In the first stages, upgraded navigational procedures should be combined with existing conventional radio navigation aids, which should be used as backup systems. Geographic and weather conditions are the primary limiting factors at the Sarajevo airport for the implementation of higher ILS approach categories. Two major factors affecting Sarajevo airport operations are weather with low visibility in the winter months and the proximity of high terrain, which limits the freedom of aircraft movement at lower altitudes. GBAS implementation would be one of the possible solutions for lowering approach minimums since there are no conditions for a higher ILS category implementation yet. Higher approach category would increase overall airport capacity, and especially could reduce a large number of cancelled flights during the winter season. This paper promotes GBAS benefits and encourages air navigation service providers, safety regulators and other users to implement such a system at Sarajevo International Airport.

\section{References}

Balvedi, G.C.; Peterson, W.; Fregnani, J. 2016. Operational Mitigation Practice To Enable the Use of GBAS on Areas Influenced By Harsh Ionosphere Phenomena. In Proceedings of the XV Simpósio de Transporte Aéreo, 1-10.

BHANSA. 2015. Sarajevo ATC Local Operational Instruction. Bosnia and Herzegovina.

AIP. 2019. AIP Bosnia and Herzegovina, BHANSA.

Blanch, J.; Walter, T.; Enge, P. 2012. Satellite Navigation for Aviation in 2025. In Proceedings of the IEEE, 1821-1830.
Circiu, M.S.; et al. 2014. Evaluation of dual frequency GBAS performance using flight data. In Proceedings of the Institute of Navigation International Technical Meeting 2014, 645-656.

Dautermann, T. 2014. Civil air navigation using GNSS enhanced by wide area satellite based augmentation systems, Progress in Aerospace Sciences 67: 51-62.

Džunda, M.; Dzurovcin, P.; Ondruš, M. 2019. Economic analysis of the operation of the navigation infrastructure of M. R. Štefanik Airport. In Proceedings of the NTinAD 2019 - New Trends in Aviation Development 2019 - 14th International Scientific Conference, 26-29.

Felux, M. 2018. Total System Performance of GBAS-based Automatic Landings. Doctoral dissertation, Technische Universität München.

Felux, M.; Dautermann, T.; Becker, H. 2013. GBAS approach guidance performance - A comparison to ILS. In Proceedings of the Institute of Navigation International Technical Meeting 2013, 409-414.

Fernández-Hernández, I.; et al. 2019. Increasing international civil aviation resilience: A proposal for nomenclature, categorization and treatment of new interference threats. In Proceedings of the ION 2019 International Technical Meeting Proceedings, 389-407.

Feuerle, T.; Stansiak, M.; Lipp, A. 2016. GBAS interoperability trials and multi-constellation/multifrequency ground mockup evaluation. In Proceedings of the 6th SESAR innovation days, Technical University of Delft, the Netherlands, 1-8.

Horozovic, D.; Natras, R.; Tabakovic, A. 2018. Solar Flare Effect on the Ionosphere and GNSS Positioning Accuracy in Western Balkan Region. In Proceedings of the First western Balkan conference, Tirana, Albania 3-4 October, 238-246.

ICAO. 2013. Guide for Ground Based Augmentation System Implementation. International Civil Aviation Organisation, Montreal, Canada. 31 p. 
ICAO. 2018. Concept of operations (CONOPS) for dual-frequency multi-constellation (DFMC) global navigation satellite system (GNSS). ICAO Navigation Systems Panel, ICAO, Montreal, Canada. 49 p.

Jeong, M.S.; Bae, J.; Jun, H.S.; Lee, Y.J. 2016. Flight test evaluation of ILS and GBAS performance at Gimpo International Airport, GPS solutions 20(3): 473-483.

Karaim, M.; Elsheikh, M.; Noureldin, A.; Rustamov, R. B. 2018. GNSS Error Sources. Multifunctional Operation and Application of GPS, Rustamov, RB, Hashimov, AM, Eds, 69-85.

Kim, T.H.; Sin, C.S.; Lee, S. 2012. Analysis of effect of spoofing signal in GPS receiver. In Proceedings of the 12th International Conference on Control, Automation and Systems, 2083-2087.

Milosevic, D.; Bajic, S.; Radonjic, Z.; Fukuta, N. 1986. Experiment of Supercooled Fog Dispersal at Sarajevo Airport and Skiing Slopes of the 14th Winter Olympic Games, The Journal of Weather Modification 18(1): 34-39.

Näs, A.; et al. 2017. Potential benefits of deploying a ground based augmentation system (GBAS) at Stockholm Arlanda airport. Swedavia Airports, Sweden, 44 p.

Natras, R.; Horozovic, D.; Mulic, M. 2019. Strong solar flare detection and its impact on ionospheric layers and on coordinates accuracy in the Western Balkans in October 2014, SN Applied Sciences 1(1): 49.
FAA. 2014. Ground-Based Augmentation System (GBAS) Action Team Report. Performance-based operations Aviation Rulemaking Committee. Federal Aviation Authorities. 54 p.

Sabatini, R.; Moore, T.; Ramasamy, S. 2017. Global navigation satellite systems performance analysis and augmentation strategies in aviation, Progress in Aerospace Sciences 95: 45-98.

Šabić, M. 2016. Aircraft and aircraft systems. [In Bosnian: Zrakoplovizrakoplovni sistemi]. Faculty of Transport and Communications. 332 p.

Sayim, I.; Kavzoglu, T.; Sahin, E. 2015. GBAS Availability Analysis for the Trabzon Airport Using True Terrain Masking Data, In Proceedings of the 7th International Conference on Recent Advances in Space Technologies, 117-121.

Smaja, L. 2015. GBAS CAT II-III Functional Descriptions Update Report. EUROCONTROL, Brussels. 88 p.

Transport Canada. 2011. Manual of All Weather Operations (Categories II and III). Fourth Edition, Transport Canada. 39 p. 